\title{
Transformaciones, retratos y experiencias: una educación militar sin fronteras ${ }^{1}$
}

\author{
https://doi.org/10.21830.9789585350663.01
}

Luz Adriana Albornoz Rodríguez ${ }^{2}$
Wendy Vanessa Méndez Velásquez ${ }^{3}$
John Alexander León Torres

Escuela de Armas Combinadas del Ejército

\begin{abstract}
Resumen. El objetivo del presente trabajo es analizar los procesos de aprendizaje mediados por tecnología y el impacto de las herramientas tecnológicas en la formación de los oficiales y suboficiales de la Escuela de Armas Combinadas del Ejército, así como el tránsito y las transformaciones que esto ha implicado en su cotidianidad y en el marco de la emergencia sanitaria generada por la Covid-19. Los materiales y métodos utilizados en
\end{abstract}

1 Este capítulo forma parte de los resultados del proyecto de investigación "Uso y apropiación de Tic: estrategias de engagement y docentes influencer", del Grupo de Investigación en Capacitación Militar (GICAM), de la Escuela de Armas Combinadas del Ejército (EsACE), registrado con el código COL0160714 de Minciencias. Los puntos de vista y los resultados de este capítulo pertenecen a los autores y no reflejan necesariamente los de la EsACE o el Ejército Nacional de Colombia.

2 Licenciada en Educación Básica con Énfasis en Ciencias Sociales de la Universidad Pedagógica Nacional. Especialista en Entornos Virtuales de Aprendizaje del Centro de Altos Estudios Universitarios. Magíster en Desarrollo Educativo Social de la Fundación Centro Internacional de Educación y Desarrollo Humano. Actualmente cursa sus estudios en el Doctorado Interinstitucional en Educación de la Universidad Pedagógica Nacional. Asesora de investigación de la Escuela de Armas Combinadas del Ejército. Docente de la Maestría en Educación de la Corporación Universitaria Minuto de Dios (Uniminuto). OrCiD: https://orcid.org/0000-0002-9673-8776 - Contacto: luzalbornozrodriguez@cedoc.edu.co

3 Licenciada en Humanidades y Lengua Castellana de la Pontificia Universidad Javeriana. Periodista. Magíster en Escrituras Creativas. ORCid: https://orcid.org/0000-0002-1365-7373 - Contacto: wendymendezvelasquez@cedoc.edu.co

4 Inspector de Estudios de la Escuela de Armas Combinadas del Ejército. Profesional en Ciencias Militares para el Planeamiento de la Escuela Militar de Cadetes “General José María Córdova”. Profesional en Relaciones Internacionales y Ciencias Políticas de la Universidad Militar Nueva Granada. Especialista en Conducción y Administración de Unidades Militares del Centro de Educación Militar. Especialista en Seguridad y Defensa de la Nación de la Escuela de Guerra. Especialista en Docencia Universitaria del Centro de Educación Militar. OrCID: https://orcid.org/0000-0001-6279-8351 - Contacto: johnleontorres@ cedoc.edu.co 
esta investigación se inscriben en el enfoque cualitativo de carácter descriptivo y se basaron en un diseño metodológico etnográfico, específicamente en la etnografía rápida, puesto que esta se ajusta a los tiempos y ritmos de aprendizaje y permanencia establecidos en la Escuela para la población observada. Las técnicas utilizadas para la recolección de la información fueron: grupos de discusión, entrevista no estructurada, cuestionarios y test de estilos de aprendizaje. Asimismo, se utilizó el análisis del discurso para identificar las categorías emergentes y la información se trianguló a partir del uso de matrices (codificación abierta). El estudio concluye que volver a los sujetos a través de sus relatos permite identificar trayectorias de aprendizaje importantes, establecer rutas pedagógicas más acordes a sus necesidades educativas, orientar procesos de formación integral, así como estimar los alcances y ajustes que las propuestas curriculares del Sistema Educativo de la Fuerza deben realizar, teniendo en cuenta las experiencias de enseñanza mediadas por la tecnología que las escuelas de formación y capacitación han tenido.

Palabras clave: competencias digitales; educación militar; educación virtual; estilos de aprendizaje.

\section{Introducción}

Las necesidades actuales en educación, a propósito de la emergencia sanitaria por la Covid-19, representan un reto importante para la formación de los estudiantes en todos los niveles académicos, lo que ha generado nuevas formas de apropiación y transmisión del conocimiento, una integración de diferentes tecnologías para asegurar las actividades académicas y una alfabetización múltiple en contextos cambiantes.

Tanto las instituciones como los gobiernos han llevado a cabo diferentes estrategias para evitar el aumento de las brechas digitales, favoreciendo el acceso a equipos tecnológicos de los estudiantes con dificultades económicas, quienes generalmente se encuentran en las zonas más apartadas del país. Asimismo, Estados y empresas han financiado el acceso a internet, entre otras estrategias del sector productivo que buscan a toda costa mantener el funcionamiento de los sistemas educativos.

El informe "La educación en tiempos de la pandemia de Covid-19", realizado por la Comisión Económica para América Latina y el Caribe (CEPAL) y la Organización de las Naciones Unidas para la Educación, la Ciencia y la Cultura (UnESCO) y publicado en agosto del 2020, muestra las diferentes estrategias que los 33 países de América Latina y el Caribe adoptaron ante la 
emergencia sanitaria. Por ejemplo, a la fecha del informe, 32 países habían suspendido las clases presenciales, de este total, 29 decidieron que esta suspensión llegara a nivel nacional, y otros países, como Uruguay, Ecuador, Belice, Granada y Santa Lucía, retornaron a la presencialidad en los meses de mayo y junio. Sin embargo, en el resto de los países se mantienen modelos híbridos o con excepciones de acceso a las aulas especializadas. Esta nueva normalidad ha afectado a un total de 165 millones de estudiantes, según los datos que proporciona la UNESCO.

En cuanto a las modalidades de aprendizaje, el informe muestra que las plataformas digitales son el medio más usado para el desarrollo de las clases, generalmente, asincrónicas; por otra parte, ocupan un lugar importante la radio y la televisión.

Las cifras por estrategia de continuidad en el marco de la nueva normalidad, que de manera mayoritaria implementan los países son, de acuerdo con el informe: instrumentos de aprendizaje a distancia, 29 países; aprendizajes en línea, 26 países; aprendizaje fuera de línea, 26 países; transmisión de programas educativos por televisión o radio, 23 países; plataformas en línea, 18 países; recursos dirigidos a docentes, 15 países; entrega de dispositivos electrónicos, 8 países; y, finalmente, clases en vivo, 4 países.

Entre tanto, los datos presentados son contundentes, dado que develan que la migración a sistemas digitales es la mejor opción en tiempos de distanciamiento social, lo que representa, simultáneamente, grandes cambios en las formas de enseñanza y el papel del estudiante, toda vez que este debe autorregularse y tener una mayor capacidad de adaptación, aspectos de especial impacto cuando se ha estado en las periferias del acceso y el uso de la tecnología.

En este contexto, las instituciones de educación superior han adelantado diferentes programas de apoyo para sus estudiantes y docentes, con el fin de crear ambientes organizacionales y de aprendizaje adecuados para el desarrollo armonioso de las funciones sustantivas de docencia, investigación y proyección social. Esta labor también la ha llevado a cabo la Escuela de Armas Combinadas del Ejército (EsACE), al fortalecer el uso de herramientas tecnológicas con fines pedagógicos como lo son las plataformas virtuales CEDOC 360 y Blackboard, a través de las cuales se capacita a todo el personal militar en los diferentes cursos de ascenso. La oferta académica de la Escuela incluye dos especializaciones y 
siete cursos militares. Estos programas de educación complementaria pueden ser cursados por oficiales y suboficiales del Ejército colombiano, así como de otros ejércitos con los que se tengan convenios activos.

Esta amplia oferta contribuye con los procesos de profesionalización y transformación que durante los últimos años viene adelantando el Ejército Nacional, razón por la cual el Sistema Educativo de la Fuerza contempla no solo campos de formación diferenciadores, sino también su integración, para permitir el desarrollo de competencias y habilidades genéricas y específicas, entre las que se encuentra el uso de las Tecnologías de la Información y la Comunicación (Tic). Del mismo modo, se ha evidenciado la necesidad de articular las experiencias y conocimientos previos de los estudiantes con las mediaciones digitales, hacia una educación sin fronteras, que responda a los desafíos de la sociedad del conocimiento en la era digital y a las necesidades de seguridad y defensa de la nación.

En este orden de ideas, el presente capítulo pretende dar a conocer el impacto de las herramientas tecnológicas en la formación de los oficiales y suboficiales de la Escuela de Armas Combinadas del Ejército, así como el tránsito y las transformaciones que esto ha implicado en su cotidianidad, en el marco de la emergencia sanitaria. Además, muestra la transición que se da entre ser visitante digital y convertirse en residente digital, transformación que da cuenta de los procesos de subjetivación, hallados tras una investigación cualitativa que incluyó el uso de instrumentos específicos como etnografía rápida, entrevista, historias de vida (relatos), cuestionarios y grupos focales, los cuales fueron aplicados a los estudiantes de la Esace.

Lo anterior representa un avance significativo en cuanto al comportamiento y la adaptabilidad que han tenido los estudiantes, a partir de las estrategias que se han venido implementando en la capacitación brindada en la Escuela. Indudablemente, la educación virtual es un escenario articulador en el cual se conjugan los saberes teóricos y prácticos con las mediaciones tecnológicas y digitales, hacia una interacción real que propicie nuevas formas de aprendizaje.

Así pues, la educación virtual nos ofrece hoy día un océano de posibilidades para el logro no solo de las metas del milenio, [...] sino también para armonizar y poner en juego la verdadera unidad en la diversidad, propia del ser 
humano, a través de infinidad de procesos cognitivos, reales, simbólicos y virtuales. (Nieto, 2012, p. 146)

Ante lo mencionado, el presente capítulo se ocupa de identificar y analizar esa diversidad, no solo en cuanto a procesos simbólicos y su relación con el aprendizaje remoto y virtual, sino que, además, busca articular las situaciones particulares de los estudiantes, sus historias de vida y los relatos que denotan una experiencia previa en la construcción de su conocimiento, el aprendizaje significativo, la implementación de las tecnologías y la transición de las áreas de combate a las aulas virtuales.

La educación militar sin fronteras cobra sentido en la medida en que está llegando a todas las regiones del país a través de la tecnología; sus estudiantes (provenientes de diversas zonas) forman parte del personal que se capacita y actualiza su conocimiento, pese a la escasa relación con las tecnologías con fines pedagógicos y formativos, dado que su capacitación ha estado mayormente enfocada a la tecnología de las operaciones y el combate. Por tanto, es interesante analizar cómo se ha dado esa transición de cambio de contexto: del fusil a los ambientes virtuales de aprendizaje; reto al que le han apostado y que ha transformado considerablemente su experiencia educativa y subjetiva.

\section{Marco teórico}

El horizonte teórico de esta investigación lo conforman los aportes de las teorías cognitivas del aprendizaje, en especial los postulados del psicólogo y pedagogo estadounidense Ausubel (1978). Asimismo, se integran los aportes de Díaz y Hernández (2010), quienes profundizan en el aprendizaje situado y las estrategias didácticas para la enseńanza, y las contribuciones de Daniel Cassany (2012), con respecto a las competencias básicas para una literacidad crítica, siendo estos últimos, aspectos fundamentales en las prácticas escriturales y, en general, en el aprendizaje basado en el intercambio abierto (Cobo, 2007).

Considerando que la presente investigación analiza el impacto del uso de las herramientas tecnológicas en los estilos de aprendizaje de los oficiales y suboficiales de la ESACE, además de las experiencias y transformaciones que esto ha representado en el marco de la emergencia sanitaria, se incluye como 
referente teórico el abordaje narrativo de Jerome Brunner (2013) y Bolívar (2002), los cuales permiten recuperar las experiencias educativas de los oficiales y suboficiales, para dar cuenta de los tránsitos, retos, aprendizajes, experiencias y transformaciones. De igual forma, los postulados de Aranguren y Ricoeur (2009), quienes defienden la narrativa del yo como una posibilidad de existir de otro modo, de otras formas, lo que, como consecuencia, posibilita las configuraciones subjetivas; Barthes (1977), quien relaciona de manera exponencial el relato como un elemento presente en todos los contextos y del que parte la historia de la humanidad que, evidentemente, no puede desligarse ni desarticularse de las formas propias del aprendizaje; y, finalmente, Bruner (2003), con la relación entre contar historias y la configuración de identidades y realidades a partir de los acontecimientos y su impacto en la existencia y la configuración subjetiva.

Esta perspectiva teórica y metodológica hace énfasis en el potencial que tiene la narrativa en la construcción de la realidad y como fuente de investigación en educación.

\section{Sobre el aprendizaje}

Desde la perspectiva cognitiva, el aprendizaje es dinámico, significativo, estratégico y diverso, todo lo opuesto al conductismo. Esta visión renovada pone el acento en la manera como el estudiante aprende, es decir, la forma como incorpora la nueva información a sus esquemas cognitivos de manera sustantiva y no arbitraria. Por ello, las metodologías de enseńanza (estrategias) y recursos que el docente presenta al estudiante tienen gran influencia en el proceso. En concordancia con esto, la presente investigación analiza los materiales y su estructura, dado que la mediación a través de tecnología implica nuevas prácticas discursivas y estrategias digitales que permiten un uso pedagógico de los artefactos.

Siguiendo con los postulados de la tradición cognitiva, el aprendizaje del estudiante puede darse de dos modos: repetitivo o memorístico, y significativo. El primero de ellos se caracteriza por un aprendizaje literal (al pie de la letra), por ejemplo, una dirección, un número telefónico, una receta. El segundo tipo de aprendizaje es aquel que se basa en ideas expresadas simbólicamente y que 
interactúan de manera sustantiva y no arbitraria con lo que el aprendiz ya sabe. Sustantiva quiere decir no literal, que no es al pie de la letra, y no arbitraria significa que la interacción no se produce con cualquier idea previa, sino con algún conocimiento, específicamente relevante ya existente en la estructura cognitiva del sujeto (Moreira, 2012, p. 30).

Ahora bien, la literatura considera importante el aprendizaje receptivo, puesto que este hace énfasis en la adquisición de productos acabados de información (Hernández, 1998) y, en el caso particular de la investigación, este tipo de aprendizaje es recurrente. El último tipo de aprendizaje es el más conocido y atribuible a los procesos de desarrollo de los niños, aunque no es exclusivo de su rango etario: el aprendizaje por descubrimiento, en el que la información debe ser descubierta, dado que no se presenta en su forma final, y luego se incorpora a las estructuras cognitivas.

Entre tanto, en los diferentes tipos de aprendizaje los subsunsores, o ideas ancla, son fundamentales porque permiten otorgarle significado al nuevo conocimiento. $\mathrm{Al}$ ser conocimientos específicos existentes en la estructura del sujeto, favorecen la interacción y por tanto el aprendizaje. Valga precisar que esta interacción dinámica, entre el conocimiento existente y el nuevo, genera nuevas significaciones, asunto importante en esta teoría de aprendizaje.

Ahora bien, el subsunsor (conocimiento previo del estudiante) puede ser una imagen, un modelo, una proposición, una concepción, entre otros. Los subsunsores son amplios o diferenciados, así, forman un conjunto jerárquicamente organizado y dinámico, que da forma a la estructura cognitiva que lleva a cabo la diferenciación progresiva y la reconciliación integradora. La primera otorga nuevos significados al subsunsor, gracias a las interacciones sucesivas de este con otros, generando niveles de complejidad y diferenciación, lo que permitirá dar anclaje a nuevos aprendizajes. La reconciliación integradora, como proceso simultáneo de la diferenciación progresiva, busca "eliminar diferencias aparentes, resolver inconsistencias, integrar significados, hacer superordenaciones" (Moreira, 2012, p. 35).

En la figura 1 se aprecia la relación entre los diferentes tipos de aprendizajes y se muestra la diversidad en su tipología: 


\begin{tabular}{|c|c|c|c|}
\hline $\begin{array}{l}\text { Aprendizaje } \\
\text { significativo }\end{array}$ & $\begin{array}{l}\text { Clarificación de relaciones } \\
\text { entre conceptos. }\end{array}$ & $\begin{array}{l}\text { Instrucción auditorial } \\
\text { bien diseñada. }\end{array}$ & Investigación científica. \\
\hline \multirow{3}{*}{$\begin{array}{l}\text { Aprendizaje } \\
\text { memorístico }\end{array}$} & $\begin{array}{l}\text { Conferencias o la mayoría } \\
\text { de las presentaciones en } \\
\text { libros de texto. }\end{array}$ & $\begin{array}{l}\text { Trabajo en el laboratorio } \\
\text { escolar. }\end{array}$ & $\begin{array}{l}\text { Mayoría de la investigación } \\
\text { o la producción intelectual } \\
\text { rutinaria. }\end{array}$ \\
\hline & Tablas de multiplicar. & $\begin{array}{l}\text { Ampliación de fórmulas } \\
\text { para resolver problemas. }\end{array}$ & $\begin{array}{l}\text { Soluciones de acertijos por } \\
\text { ensayo y por error. }\end{array}$ \\
\hline & Aprendizaje receptivo & $\begin{array}{l}\text { Aprendizaje por } \\
\text { descubrimiento(guiado) }\end{array}$ & $\begin{array}{l}\text { Aprendizaje por } \\
\text { descubrimiento } \\
\text { (autónomo) }\end{array}$ \\
\hline
\end{tabular}

Figura 1. Dimensiones y tipos de aprendizaje.

Fuente: tomado de Díaz y Hernández (2010).

Teniendo en cuenta lo anterior, el aprendizaje significativo requiere de tres condiciones elementales: (1) el material debe guardar una significatividad lógica o potencial; (2) debe existir una significatividad psicológica, esto es, que "entre el material de aprendizaje y los conocimientos previos de los alumnos exista una distancia óptima para que ellos puedan encontrarle sentido (Hernández, 1998, p. 139), y, finalmente, (3) debe existir un esfuerzo y disponibilidad por parte del alumno.

En el caso del aprendizaje de los adultos (andragogía), la literatura indica que el aprendizaje significativo por recepción es el modelo predominante, debido a la naturaleza del contenido, su complejidad y por los medios en los que se socializan los resultados científicos. Debido a la complejidad del contenido (abstracción), los adultos requieren un tiempo eficiente de aprendizaje y el descubrimiento guiado puede requerir mayor tiempo, lo que en ocasiones es imposible por las condiciones socioeconómicas que limitan la permanencia de los adultos en los diferentes ciclos de formación. Por otra parte, los conocimientos científicos se han presentado en libros, revistas o congresos, lo que convierte la oralidad y la escritura en sus formas dominantes de socialización, asunto que en la era digital se extiende a formatos que se caracterizan por ser masificados y simultáneos, tal como lo señala Moreira (2012):

En la enseńanza secundaria y superior predomina fuertemente el aprendizaje receptivo. Aun cuando la enseñanza está centrada en el alumno, como se defiende hoy, el aprendizaje seguirá siendo receptivo. La enseńanza centrada en el alumno no es sinónimo de aprendizaje por descubrimiento. Aprendizaje 
por descubrimiento no lleva necesariamente al aprendizaje significativo.

Aprendizaje receptivo no es lo mismo que aprendizaje mecánico. (p. 42)

Teniendo en cuenta lo anterior, el uso de herramientas Tic no garantiza que se aprenda ni se genere una mayor motivación hacia el aprendizaje; en cambio, las herramientas tecnológicas pueden convertirse en un factor de distracción si no se establecen objetivos pedagógicos y se trazan rutas claras y concretas para el aprendizaje. Por ello, la autorregulación del aprendizaje cumple un papel importante.

Asimismo, es indispensable diferenciar los tipos de aprendizaje — representacional (de representaciones), conceptual (de conceptos) y proposicional (de proposiciones) — de las tres formas en que se produce - por subordinación, por superordenación y de modo combinatorio- A continuación, la tabla 1 presenta a modo de esquema las diferencias.

Tabla 1. Tipos y formas del aprendizaje significativo

\begin{tabular}{ll}
\hline Tipos & Formas \\
\hline Representacional & Subordinación \\
\hline Conceptual & Superordenación \\
\hline Proposicional (de proposiciones) & Modo combinatorio \\
\hline
\end{tabular}

Fuente: Ausubel (1978).

Entre tanto, y con el fin de analizar el fenómeno de la educación mediada por tecnologías y las apuestas teóricas por establecer los nuevos escenarios educativos, la investigación consideró importante articular la tradición cognitiva con algunos principios a los que se refiere la pedagogía de la interactividad (Aparici \& Silva, 2012), en la cual el carácter colaborativo, activo y propositivo del estudiante se opone a la pedagogía de la transmisión. Desde la perspectiva de la educación en línea, se supera la mecánica industrial que se le atribuye a la educación convencional, toda vez que esta masifica y estandariza. Así mismo, las pedagogías críticas han mostrado cómo este tipo de educación no permite el cambio de las condiciones sociales, puesto que reproduce el sistema de exclusión. 
En este contexto, la pedagogía de la interactividad pretende hacer un mayor énfasis en la comunicación y las relaciones recíprocas entre estudiantes y docentes, puesto que no hay un magiocentrismo, sino una construcción colectiva del conocimiento. Todo ello evidencia los rasgos de una pedagogía contemporánea, en la que se comprenden las dinámicas de la enseñanza y el aprendizaje desde el diálogo de saberes, en el que el estudiante tiene un papel más activo en la exposición, socialización y construcción de los contenidos a aprender. De acuerdo con Aubert (2008; citado por Aparici \& Silva, 2012):

En la actual sociedad de la información, es a través del diálogo con las personas 'no expertas' como es posible el desarrollo de teorías más inclusivas y científicas. No hay personas expertas que posean todo el conocimiento social y cultural necesario para realizar propuestas eficaces para todas las personas. Todos y todas podemos aportar argumentos desde nuestras diferentes experiencias y recursos culturales. (p. 53)

Este cuestionamiento al monopolio del saber no implica su relatividad ni el desconocer lo que la ciencia ha logrado hasta el momento, pero sí pone el énfasis en las diversas fuentes de conocimiento, en la inclusión de sistemas y paradigmas no convencionales que puedan dar cuenta de nuevas epistemologías. Por tanto, no es un llamado a la relatividad propia de la sociedad líquida (Bauman, 1999).

En consecuencia, la consolidación de estos escenarios de interactividad evidencia diversas posibilidades de exploración, cocreación y formación de comunidades de aprendizaje desterritorializadas, móviles y adaptables, que responden a lógicas conectivistas. En ese sentido, las experiencias de los colectivos y de las personas que encuentran en la web un lugar para socializar sus proyectos, ideas o experiencia muestran el potencial para recuperar trayectorias de aprendizaje, de tal modo que el saber no es una producción estática, sino que, por el contrario, en esta sociedad tecnologizada, es el resultado de la interacción a escalas inimaginables.

Con la idea de que la web es un escenario múltiple, móvil, abierto de cocreación, hipertextual, de navegación multidireccional y múltiples conexiones, la literacidad crítica ocupa un lugar importante para comprender las nuevas alfabetizaciones. Para Cassany (2012), el lector debe asumir que hay una diversidad de interpretaciones que configuran los textos y, por ello, se 
deben construir interpretaciones sociales en las que se logren identificar las pluralidades. Así mismo, se debe reconocer la intención comunicativa e ideológica del autor de los textos que se leen, rastrear y fijarse en los elementos implícitos del discurso, contrastar las fuentes y "saber que comprender y creer estar de acuerdo son cosas diferentes” (p. 132).

\section{Retratos, relatos y experiencias}

Contar es como vivir y vivir es como contar o, mejor
dicho, contarse, de manera que el mundo vivido y el
arrado se solapan inevitablemente. Somos o, al menos,
nos figuramos ser nuestra propia novela, la "narración
narrante" de nuestra vida
ARANGUREN Y RICOEUR (GóMEZ, 20I6).

El aprendizaje está simultáneamente articulado con las experiencias del sujeto y las vivencias que lo atraviesan a lo largo de su vida. Se mencionó anteriormente que el aprendizaje es dinámico, significativo y diverso, esto supone la posibilidad de que los sujetos se apropien cada uno de los saberes que adquieren en pro de una transformación que no solo se relaciona con el escenario académico y formativo, sino con un escenario de vida, existencia y transformación. Es decir, la relación y el binomio entre el saber con su realidad cotidiana.

El ejercicio investigativo que se desarrolló estuvo fundamentalmente cimentado en la realidad propia de cada estudiante, teniendo en cuenta que sus contextos están mediados y atravesados por una formación militar enfocada en ser garantes de la seguridad y la defensa del país, y cuyas competencias se han enfocado principalmente en dicho propósito. Por tanto, no supone ser una obviedad que tengan experiencia y trayectoria con respecto a las exigencias de la era digital (en la mayoría de los casos) y lo que respecta a la alfabetización digital para su formación profesional.

Por tanto, las historias de vida y los relatos, al articularse, establecen la posibilidad de conocer y profundizar en narrativas subjetivas que pueden permitir comprender no solamente al estudiante mediado por la tecnología, sino al estudiante militar que está en proceso de aprender y adaptarse a la tecnología, 
a las plataformas virtuales, al aprendizaje autónomo y a las herramientas digitales, así como a la forma en que vincula este escenario a su realidad inmediata, teniendo en cuenta que muchos de sus contextos cotidianos han estado determinados por fusiles, territorios en guerra y un pelotón, factores protagónicos en sus procesos formativos como militares. Por tanto, se considera elemental tomar registro de ese tránsito formativo y de configuración de los estudiantes.

De acuerdo con Barthes (1996), "el relato está presente en esas formas casi infinitas, está presente en todos los tiempos, en todos los lugares, en todas las sociedades; el relato comienza con la historia misma de la humanidad" (p. 2). En esa medida, para proponer un avance significativo en la construcción de una educación que apueste por una transformación y oriente al cumplimiento de los retos de la sociedad actual, que involucre el uso de las Tic y que además identifique los estilos de aprendizaje, conviene tomar en consideración esas experiencias previas que han configurado y consolidado el aprendizaje formativo de los estudiantes. De lo contrario, no se podría evidenciar una transformación y un aprendizaje significativo que enriquezcan la experiencia del sujeto que aprende.

Por otra parte, la posibilidad de contar historias, relatar y transmitir las interpretaciones del mundo y la realidad mediadas por la experiencia resulta esencial para que los sujetos articulen su aprendizaje y lo comprendan como un proceso no acabado, sino como un proceso de vida que no se agota. Allí, en el relato, cada acontecimiento es significativo y transformador.

En el caso que nos compete, la Esace capacita a personal militar de todo el país. Estos hombres y mujeres, que pertenecen a diferentes armas y son orgánicos de otras escuelas, aprenden en conjunto y articulan sus experiencias dentro del rol militar, con el aprendizaje y la capacitación permanente que reciben en su proceso y vida dentro de la Fuerza.

Esto supone, entonces, que las historias de vida no radican únicamente en la forma como interpretan una realidad, sino también en su proceso formativo, para dar respuesta al compromiso adquirido y a la realidad nacional en la que están inmersos. Estos factores resultan ser fundamentales para la construcción de una educación significativa, que dé sentido y que posibilite la exploración de los acontecimientos como mediaciones que transformen y potencien sus competencias. 
Los seres humanos dan sentido a su mundo cotidiano contando historias sobre sí mismos. Ese contar historias va configurando su identidad, precisamente en el trabajo de relatar lo que les pasa y lo que los sujetos hacen con lo que les pasa. El sujeto se constituye cuando está relatando su propia vida. Allí se autointerpreta buscando ordenar y dar significado a la propia existencia. (Bruner, 2003)

Ante lo anteriormente expuesto, la presente investigación buscó centrarse en las experiencias previas de los estudiantes y sus múltiples escenarios evocativos, los cuales permitieron recrear y comprender de mejor manera los procesos subjetivos, a través de la narrativa y la construcción del relato e historias de vida, además de evidenciar la forma como estos factores influyen en el tránsito que esto despliega hacia formas particulares de aprendizaje, de formación, de estructuración del conocimiento y, sobre todo, de la implementación de las herramientas tecnológicas como escenario cotidiano de interacción y aprendizaje.

Cabe anotar que a través del relato los estudiantes pudieron dar cuenta de identidades propias que construyen como sujetos para narrar de formas particulares sus experiencias formativas, cotidianas y de la comprensión de sí mismos, por cuanto "el interés de indagación tiene que ver con la captación y reconstrucción de significados que se van configurando en el mismo proceso narrativo a partir de la experiencia de los mismos actores" (Granados, 2016, p. 8).

En este orden de ideas, incluir el relato y las experiencias significativas dentro del aprendizaje y la formación virtual, mediada a través de las tecnologías, devela un nuevo horizonte y presenta un panorama que apuesta por propuestas y estrategias que no ocupen y centren toda su atención en el recurso (la tecnología), sino en el protagonista del proceso formativo (el estudiante) y su formación con ese conocimiento y el saber que está adquiriendo. En otras palabras, no se debe enajenar y olvidar que detrás de los dispositivos tecnológicos existen sujetos pensantes, que sienten y que perciben e interpretan una realidad. Si no se pierde de vista ese principio de subjetividad y de identidad de los estudiantes, el aprendizaje formativo se vinculará inmediatamente con la legitimidad del ser, con la educación que no limita y una formación que enriquece integralmente a ese sujeto que aprende.

Aun cuando el hombre tenga una gran variedad de pensamientos, y tales que de ellos otros hombres, así como él mismo, pueden recibir provecho y gusto, 
sin embargo, esos pensamientos están alojados dentro de su pecho, invisibles y escondidos de la mirada de otros hombres, y, por otra parte, no pueden manifestarse por sí solos [...] fue necesario que el hombre encontrara unos signos externos sensibles, por los cuales esas ideas invisibles de que están hechos sus pensamientos pudieran darse a conocer a otros hombres, resulta pues que el uso de la palabra consiste en que sean señales sensibles de las ideas; y las ideas que se significan con las palabras son su propia e inmediata significación. (Locke; citado por Acero, 1998, p. 24)

De esta manera, el relato les atribuye entonces un lugar en el mundo. La narrativa del yo aporta una nueva mirada a la educación y formación del personal militar, y apuesta por una formación sin fronteras, sin limitaciones, con lo cual contribuye a la tarea de aprender a nombrar lo que nos sucede y a la experiencia de lo que se hace con eso que nos sucede.

\section{Métodos}

Este capítulo es el resultado de una investigación de tipo cualitativo que se inscribe en la exploración en el campo y la etnografía educativa, cuyo carácter interpretativo permitió desarrollar, a través de diversos instrumentos, un análisis documental en torno a los desafíos de la incorporación de las Tic en los procesos formativos de los estudiantes (oficiales y suboficiales) de la Escuela de Armas Combinadas del Ejército, así como también los aspectos académicos y pedagógicos que han estado inmersos en dicho proceso.

En esa medida, y de acuerdo con Irene Vasilachis (2006), "la investigación cualitativa no constituye un enfoque monolítico, sino un espléndido y variado mosaico de perspectivas de investigación" (p. 16), lo cual hace posible el uso de diversas estrategias e instrumentos para la recolección y el análisis de datos. Con base en estos aspectos, la indagación permitió identificar los momentos cotidianos de los estudiantes y su relación con las nuevas tecnologías en educación implementadas para su proceso formativo.

Se puede afirmar, además, que la investigación es cualitativa porque comprende las distintas percepciones acerca de la realidad, el significado y el sentido que han construido los estudiantes de la EsaCE a partir de sus experiencias, para, de este modo, interpretar y configurar descripciones, reflexiones, sentimientos e impresiones que los individuos realizan de su proceso formativo y la construcción de su conocimiento. De otro lado, la investigación es multi- 
modal, puesto que la aplicación que se le ha dado a la investigación no parte de un único método o estrategia, sino que, por el contrario, surge a partir de diversas herramientas de análisis documental que se tuvieron en cuenta para dicho fin.

Es el caso de la entrevista no estructurada, que "se trata de una relación social a través de la cual se obtienen enunciados y verbalizaciones en una instancia de observación directa y de participación [...] las entrevistas no estructuradas son sospechadas, precisamente, porque aparecen como un instrumento personalizado" (Guber, 2001, p. 76). Por su parte, los grupos de discusión propiciaron el diálogo y el debate con el fin de conocer las diferentes posturas frente al tema abordado y la interacción entre pares, teniendo en cuenta que

los grupos de discusión son un dispositivo analizador cuyo proceso de producción es la puesta de colisión de los diferentes discursos y cuyo producto es la puesta de manifiesto de los efectos de la colisión (discusión) en los discursos personales (convencimiento: convencido el que ha sido por el grupo) y en los discursos grupales (consenso) (Ibáñez, citado por Arboleda, 2008, p. 71).

De este modo, los grupos de discusión permitieron identificar las experiencias, intereses, debilidades y propuestas que dieron espacio a la problematización y reflexión, a partir de los interrogantes propuestos en relación con la experiencia y el aprendizaje a través de la implementación de la tecnología.

Por su parte, las historias de vida como métodos biográficos indagan e interpretan los hechos y las experiencias de vida de los sujetos, que no solamente permiten identificar, conocer y comprender la relación e interacción con el grupo y el contexto social determinado, sino además otros aspectos que lo configuran: familia, entorno, cultura, identidad. Por tanto, las historias de vida de los estudiantes enriquecieron el análisis y las discusiones previas, develando aspectos específicos que, a simple vista, no fueron identificados y que, por tanto, aportaron de manera significativa a la presente construcción. Cabe recordar, como anota Vasilachis (2006), que

la investigación cualitativa se interesa por la vida de las personas, por sus perspectivas subjetivas, sus historias, por sus comportamientos, por sus experiencias, por sus interacciones, por sus acciones, por sus sentidos e interpreta a todos ellos de forma situada, es decir, ubicándolos en el contexto particular en el que tienen lugar. (p. 34) 
A su vez, el análisis documental y la triangulación de la información permitieron plasmar e identificar hallazgos en torno a la formación y las experiencias de los estudiantes mediante el uso de las tecnologías.

La investigación tuvo también un componente holístico, pues tomó en consideración las transformaciones y la subjetividad de cada estudiante, de manera que recopiló comportamientos, sucesos, expectativas y conocimientos. Entre otras cosas, el enfoque asignado a la investigación logró una aproximación a lo nuevo, permitió desarrollar diversas nociones y contrastar teorías en torno a los aspectos elementales abordados: aprendizaje, tipos de aprendizaje, estilos de aprendizaje, adaptación y experiencia a las nuevas Tic y la transformación que esto ha representado para los estudiantes de la EsACE.

De otra parte, la investigación tuvo como base sólida la etnografía rápida, cuya esencia radica en el uso de un menor tiempo y con diferenciales importantes en sus características y atributos principales:

La etnografía rápida surgió de la etnografía tradicional con la intención de generar conocimiento en un tiempo muy corto, para hacerse compatible con los compromisos de planificación de proyectos desde diversos flancos de la sociedad [...] permite identificar los elementos que aportan significados en tiempos relativamente cortos a comparación de los estudios tradicionales que tienen al menos dos años de trabajo de campo. (Páramo, 2016, p. 146)

Ante lo anteriormente expuesto, la investigación que se realizó con los oficiales y suboficiales de la EsACE del Curso Profesor Militar se completó en aproximadamente dos meses, teniendo en cuenta que los cursos de ley y de capacitación militar tienen una corta duración y están en constante rotación del personal militar. No obstante, los atributos y las características del enfoque cualitativo permitieron profundizar en la indagación, a partir de los instrumentos aplicados (ya mencionados), así como en la comprensión de los impactos en el proceso de aprendizaje, por medio de la realización de cuestionarios, grabaciones y la cartografía social pedagógica como insumos.

De igual forma, la etnografía rápida permite hacer una recolección sistemática de los datos cualitativos para profundizar e identificar esas relaciones que, en ocasiones, no pueden ser comprendidas a simple vista; además, al mismo tiempo, contribuye a la identificación y detección de fortalezas, debilidades, críticas y retos a través de evaluaciones rápidas, aspecto que fue posible 
lograr con cuestionarios y la socialización entre pares que los estudiantes lograron consolidar, a partir de unas preguntas base para los grupos focales durante las clases.

Como resultado, la investigación permitió construir imágenes completas y holísticas, analizar las perspectivas y profundizar en situaciones cotidianas de la relación de los estudiantes con la mediación tecnológica dentro de su proceso formativo, atendiendo sobre todo al contexto particular en el que aquellos se encuentran inmersos, pues no todos cuentan con los mismos conocimientos con respecto al uso de las plataformas, las herramientas educativas y los dispositivos tecnológicos. En este sentido, el aspecto esencial de la indagación y exploración consistió en identificar los retos y el impacto de este escenario, teniendo en cuenta que no es un espacio reconocido por todos. en el cual difieren sus formas particulares para aprender y acercarse al conocimiento.

Entre tanto, fue indispensable articular una reflexión permanente con los estudiantes con el fin de diversificar el sentido y afianzar aquellas experiencias subjetivas que, de manera significativa, aportaron a las consideraciones iniciales que se desarrollaron con respecto a los retos que ha representado para ellos su aprendizaje en modalidad remota a través de las plataformas de la Esace - Cedoc 360 y Blackboard-, y dar espacio a nuevos postulados y reflexiones en torno a la "no directividad" como estrategia o situación que permite el encuentro de diversas reflexiones en pro de una nueva reflexividad (Guber, 2001).

\section{Población}

La investigación se enfocó en los estudiantes militares del Curso Profesor Militar (oficiales y suboficiales), así como en los estudiantes (suboficiales) del Curso de Capacitación Avanzada (CApavan) de la Esace.

La población seleccionada para el desarrollo de la investigación estuvo conformada por hombres y mujeres entre los 27 y los 50 años, provenientes de diversas zonas del país. Los instructores militares se encontraban desarrollando el Curso Profesor Militar, cuyo objetivo es capacitar y desarrollar en cada estudiante las competencias y saberes para su desempeño como docente en las diferentes escuelas de capacitación y formación del Ejército Nacional. 
Por otra parte, los suboficiales de CAPAVAN seleccionados se encontraban en curso de ascenso para optar por el grado inmediatamente superior (de sargento segundo a sargento viceprimero), el cual se lleva a cabo en un periodo de tres meses, aproximadamente, tiempo contemplado dentro de la etnografía rápida, base fundamental de esta investigación.

\section{Resultados}

En este apartado se pretende, a partir de la investigación realizada y el análisis de los resultados, retratar y dar respuesta a la transición en la formación académica y el aprendizaje de los estudiantes militares de la EsACE, que pasaron de la presencialidad a la virtualidad, y la forma como esto ha tenido incidencia en sus formas de aprendizaje y de saberse sujetos. Además de la transformación que ha representado para ellos salir de las zonas de combate y de operaciones de los diferentes territorios y zonas del país, para iniciar un proceso de capacitación y formación a través de las mediaciones tecnológicas.

Específicamente, los resultados se presentan en dos ejes reflexivos: (1) los relatos sobre el aprendizaje y (2) el tránsito entre la cartografía social-pedagógica del aprendizaje.

\section{Relatos y narrativas: de las zonas de operación a las aulas virtuales}

Como se mencionó en la introducción de este documento, las experiencias e historias de los estudiantes fueron un eje articulador para reconstruir y comprender el binomio entre la formación que han obtenido en el aula virtual durante la crisis epidemiológica, así como la que han adquirido con el paso del tiempo durante su permanencia en el área y en las diversas zonas del país. Estas trayectorias de aprendizaje son de gran importancia para generar reflexiones acerca de los diseños de los entornos virtuales, los procesos de acompañamiento y las estrategias pedagógicas para orientar a los estudiantes en la gestión del conocimiento.

Se presenta entonces la manera como dicha transición ha tenido incidencia en sus formas de aprendizaje y de saberse sujetos. Este eje de análisis muestra la reflexión de las experiencias de aprendizaje significativas y la articulación, relación e interacción con el grupo y el contexto. 
Como se ha mencionado, la cercanía a la formación mediada por las plataformas tecnológicas para los estudiantes que forman parte de la Fuerza ha sido mínima y, por tanto, su formación ha estado enfocada, especialmente, en las operaciones técnicas y tácticas. A través de los diferentes relatos que compartieron algunos de los estudiantes de la $\mathrm{EsACE}^{5}$ fue posible vislumbrar este escenario de manera más cercana y comprender que, a diferencia de la formación civil, algunos militares no cuentan con un alto nivel de experticia en el manejo de los recursos tecnológicos con propósitos pedagógicos, pero sí cuentan con amplia experiencia en el uso de las tecnologías propias de su campo profesional. Aquí, un testimonio que da cuenta de este hecho:

El cambio es muy brusco, uno estaba acostumbrado a estar con las tropas y estar ejerciendo el control y el mando con los soldados al cambio en la parte de la educación, porque se le dificulta a uno en el aspecto de que de pronto le pierde uno el ritmo, y muchas veces la parte educativa la deja uno a un lado. Al momento de estar concentrado en la parte operacional, en la parte del mando de tropa y al momento de volver otra vez a la parte educativa se le dificulta a uno otra vez implementar los hábitos educativos para volver a retomar ese conocimiento y todo lo que implica volver a leer, volver a las aulas, volver a un computador. Esa transición es un poco a veces difícil, se dificulta (SIC) (E01, octubre de 2020).

Las anteriores palabras evidencian la importancia de tomar en cuenta los conocimientos previos y la forma como se vinculan nuevos escenarios de aprendizaje, que demandan el manejo rápido de tecnologías para la formación. Los relatos obtenidos reflejan además esa transición entre utilizar el fusil en la zona de operaciones y reemplazarlo por una plataforma virtual, lo que, ciertamente, involucra escenarios completamente diferentes que dan cuenta de esa dificultad que muchas veces presentan los estudiantes de la Escuela para poder culminar de manera exitosa su proceso educativo:

Cambiar el fusil por un computador es un reto que uno tiene que asumir en la Fuerza. A uno lo preparan para trabajar en diferentes ámbitos. Cuando le toca a uno allá en el teatro de las operaciones, pues uno debe estar preparado para eso. Y después me tocó aquí, y me tocó prepararme para eso, para

5 Las entrevistas se codificaron y caracterizaron por fecha y código de acuerdo con el tipo de instrumento de recolección (entrevista) por reserva de nombre y apellido de los estudiantes. 
desempeñarme como instructor. Son situaciones que se presentan en cualquier momento en el área que le toque. (E02, octubre de 2021)

El anterior aparte pone de relieve la capacidad adaptativa de los suboficiales y oficiales del Ejército, que está en armonía con la meta que desde hace unas décadas se viene proyectando con respecto a la formación de un Ejército multimisión. Un aspecto importante del sistema educativo de la Fuerza es la articulación entre ser líder militar e instructor, dado que este último es el eje para que la pedagogía militar siga vigente. Al referirse a la instrucción hay que ubicarla en el contexto y sus características particulares, pues no se puede asociar de manera mecánica a las tradiciones conductistas, ni reducirla a un conjunto de órdenes que desconocen al otro. La instrucción es un proceso importante de orientación y liderazgo, de socialización del conocimiento a través de retomar las lecciones aprendidas y volverlas lugar de reflexión sobre las tácticas y estrategias de la conducción de la guerra.

Por su parte, un sargento viceprimero que actualmente forma parte de la ESACE afirma que la transición de la presencialidad a la virtualidad ha representado un reto significativo, especialmente para aquellos que no tenían cercanía alguna con el aprendizaje mediado por la tecnología:

En cuanto a la parte virtual, siento que [se han] favorecido con respecto a la pandemia [...] procesos [donde] algunos han tenido la oportunidad de estar un poco más cerca de sus familias, de sus casas, pero también se ha dificultado para algunas personas que durante el transcurso de su vida militar nunca han tenido la oportunidad de utilizar un computador, de encenderlo, ingresar a las plataformas virtuales, el empleo de las redes sociales, de integrarse el hombre con el computador, y entonces es aprender prácticamente uno solo. Mientras que, en la parte presencial, ya en las aulas con el resto de compañeros, [en] el grupo de trabajo [...] uno se acercaba al que más sabía y tenía conocimiento [...], pero en esta parte virtual le toca a uno solo con la materia, las ayudas y el material didáctico que nos entregan, entonces es nuevamente retomar y, en cierto modo, ser uno autodidacta. (E03, octubre de 2020)

La vida como narración sucinta es, entonces, un escenario en el que el relato toma protagonismo y evidencia las emociones, sensaciones, experiencias, recuerdos y conocimiento de los estudiantes. Aquí se entretejen realidades que muchas veces se desconocen y que influyen de manera directa en las formas de aprendizaje de los estudiantes, en su interacción con la realidad, en la forma 
como interpretan el mundo y en la manera como utilizan el conocimiento y las competencias que van adquiriendo a lo largo de su vida. Se trata de ese principio elemental de contar historias y sentir que se pertenece a algo, que se ocupa un lugar en el mundo y que a través del relato se enlaza el pasado, el presente y el futuro.

La vida tiene que ver con contar historias, con la manera como los sujetos narran historias a partir de experiencias vitales que los constituyen. El ascenso a la humanidad como construcción subjetiva pasa por esa capacidad para relatar la propia vida, atravesada por experiencias en las que se configuran tramas densas, inmersas en contextos sociales, económicos y culturales complejos en su diversidad y pluralidad. Vivir es relatar. No es posible una vida auténtica sin relato. (Granados, 2016, p. 6)

Los relatos de los estudiantes de la EsACE forjaron una ruta orientadora que permitió profundizar en aspectos personales, familiares y, primordialmente, en aquellos concernientes a su rol como militares, a partir de esa necesidad de contar y dar a conocer esas situaciones que los configuran y los hacen sujetos y seres humanos, antes que militares. Por tanto, la narrativa del yo estuvo presente de manera protagónica a lo largo de la investigación, de forma que los aspectos que se retratan aquí convocan a una reflexión permanente sobre la formación que se le está dando al personal militar y el alcance e impacto que tiene dicha formación en sus vidas. Contar historias desde los sucesos que atraviesan al sujeto involucra diferentes procesos, puesto que no es lo mismo un hombre que es estudiante que un hombre que va a la guerra y se convierte en estudiante; hay un distanciamiento existencial que configura a cada uno de manera opuesta y representa un punto de giro, una dislocación en la existencia y en la forma de aprender y de acercarse a la formación académica.

Los lineamientos de la educación militar nunca podrán articularse en su totalidad con la educación de otras instituciones de educación superior del país, encargadas de profesionalizar a la población civil, dado que el personal militar busca optimizar sus conocimientos para garantizar y velar por la seguridad del país. Aquí no se trata solamente de una capacitación desde el sujeto que aprende, sino de la forma como ese sujeto que aprende utiliza esas competencias para velar y cumplir con la misión y el compromiso adquiridos con un territorio, una comunidad, una zona específica y, en resumidas cuentas, con todo un país. 
Por tanto, es necesario que las escuelas de formación del Ejército Nacional rescaten y articulen esos relatos y experiencias de los estudiantes, para implementar estrategias y propuestas en los proyectos educativos de cada programa que cumplan con las necesidades de aprendizaje propias del personal militar, los cualifiquen de manera integral para el desempeño de su rol, les garantice una educación que apueste por la transformación de sujetos y los potencie plenamente en cada una de sus actuaciones. Un ejemplo de ello puede apreciarse en el siguiente relato:

Son situaciones totalmente diferentes, ya que en Arauca, en donde estaba, me
encontraba en una zona de orden público un poco pesado y a diario [...] tenía
uno que andar con los fusiles para arriba y para abajo, y ya al llegar aquí a la
Escuela pues cambia todo, porque ya aquí es netamente educativo y cuando
llegué aquí a la Escuela fui al curso de CpI para poderme desempeñar como
instructor, y pues es totalmente diferente, porque acá ya tiene uno que desem-
peñarse como instructor, prepararse para poder dar las clases, mientras que en
Arauca estaba uno entrenado para combatir el enemigo y acá ya uno debe estar
preparado para dar sus clases, capacitar al personal de oficiales y suboficiales.
(E04, octubre de 2020).

Como se ha evidenciado, las historias de los entrevistados van "configurando su realidad, van configurando su identidad, en ese trabajo de relatar lo que les pasa y lo que los sujetos hacen con lo que les pasa [...] se autointerpretan buscando ordenar y dar significado a la propia existencia” (Bruner, 2003).

De otra parte, la formación virtual ha representado movilización y transformación para los estudiantes que son parte de la EsACE, en la medida en que se han visto confrontados al uso permanente de los dispositivos tecnológicos y, en mayor medida, a las plataformas virtuales (CEDoc 360 y Blackboard) para poder cumplir y desarrollar las funciones específicas como estudiantes y como docentes. Así, la contingencia sanitaria por la Covid-19 ha permitido que los estudiantes se vean en la necesidad de buscar la forma de aprender y de ser usuarios digitales:

Antes de llegar a la Escuela no había tenido la oportunidad de manejar una plataforma virtual $y$, como le dije ahorita, son retos que uno como militar debe cumplir y nos toca a todos adaptarnos por cuestiones de la pandemia. Yo no tenía mucha experiencia utilizando plataformas, era prácticamente 
lo básico: ingresar, verificar una información, ingresar al correo de pronto, algo muy básico. Incluso, a la plataforma Blackboard a veces uno ingresaba a un curso a verificar una información y hasta ahí, pero de compenetrarse, de buscar, de hacer una presentación, de todo eso no se tiene experiencia. Lo más difícil, aparte de estar lejos de la familia, es que cuando uno está en el teatro de operaciones, allá en el área donde llegan las cinco de la tarde, uno solo mira árboles, monte, los compañeros, porque no se ve absolutamente más nada. (E03, octubre de 2020)

En relación con el testimonio anterior, resultan pertinentes las palabras de Granados (2016), cuando afirma:

La vida está reclamando una lectura narrativa que dé cuenta de los tránsitos de un sujeto que, en situaciones de adversidad, de lucha y de tensión, tiene la capacidad para narrar su historia. Al contar historias, los sujetos se adentran en escenarios evocativos y creativos donde recrean y reinventan lo que han vivido en clave de posibilidad y de proyecto. (p. 6)

Dicha lectura narrativa se articula con esos tránsitos que tanto oficiales como suboficiales han vivenciado en el transcurso del año y que develan situaciones de tensión y de retos permanentes, pero que, en cualquiera de los casos, ha forjado una transformación más allá de lo formativo.

Se puede agregar, además, que a partir de los relatos se hace palpable que los estudiantes, a través de las capacitaciones de la EsACE y el uso permanente de las plataformas virtuales, han asumido el reto de la formación virtual y este proceso ha significado un avance importante y complementario en su formación:

Aquí tuvimos una capacitación y ya uno se va volviendo experto en el tema de la virtualidad. Ya con lo de la pandemia nos tocó adaptarnos a la virtualidad $y$, primero, pues es un poco complicado porque uno no maneja muy bien el tema, pero ya con el curso de CaPAVAn pues ya va uno como fogueando el tema y ya le coge uno el tiro y ya es más fácil. (E04, octubre de 2020)

Finalmente, es necesario resaltar que existen oficiales y suboficiales de la EsACE que cuentan con conocimiento y experiencia en el uso de herramientas digitales para fines pedagógicos, quienes, con la situación actual del país, han fortalecido sus competencias digitales para la formación del personal militar y para contribuir con los procesos educativos y formativos de la Escuela. 


\section{Escritura y subjetividad}

El análisis de los diversos textos y ejercicios de escritura realizados por los estudiantes es otro aspecto esencial para el desarrollo de la investigación, el cual aportó de manera significativa a los aprendizajes.

Entre los factores importantes evidenciados como resultado de la práctica escritural, se destaca el aprendizaje significativo, puesto que se vinculan los contenidos de manera no arbitraria, buscando que los estudiantes desarrollaran procesos de reflexión y problematización, los cuales se llevaron a cabo durante las actividades, la articulación e interacción grupal y, principalmente, la adaptabilidad a las instrucciones de acceso y el manejo de las diferentes herramientas digitales utilizadas para dicho fin. A continuación, se presenta un ejercicio de escritura simultánea en la herramienta Padlet (figura 2).

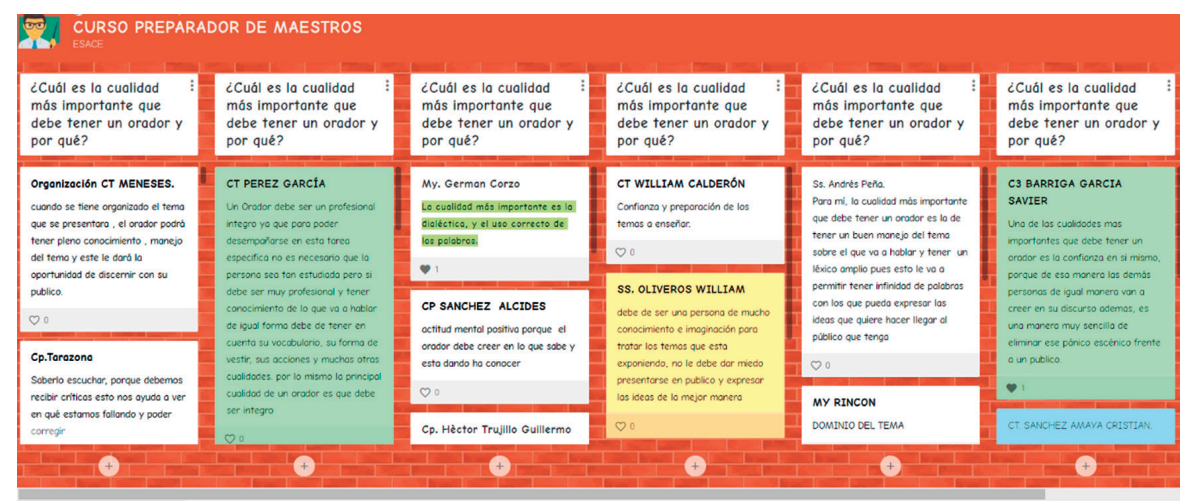

Figura 2. Ejercicio de escritura de oficiales y suboficiales en la herramienta digital Padlet. Fuente: elaboración propia.

El ejercicio anterior refleja la postura de los estudiantes en torno a las cualidades que debe tener un instructor militar en lo que atañe a su expresión oral, para lo cual, cada estudiante utilizó un cuadro o nota de texto sobre la cual manifestaba y daba a conocer su punto de vista. De esta forma, se puso de manifiesto que, cuando se fomentan espacios de escritura no forzada, los estudiantes relacionan conocimientos previos con el nuevo conocimiento que se les presenta. Esto implica que gracias a los antecedentes y las habilidades cognitivas para el aprendizaje, cada estudiante logró complementar y optimizar la comprensión de la temática, además de aportar al aprendizaje significativo del grupo a través de la interacción, el intercambio y la articulación de ideas. 
Asimismo, los participantes demostraron un aprendizaje receptivo significativo, al atender a las pautas y los lineamientos para el desarrollo de las actividades, demostrando así una importante capacidad y adaptabilidad a las herramientas digitales. En este caso, es indispensable la guía orientadora por parte del tutor y el acompañamiento y seguimiento de las actividades que se lleven a cabo.

A continuación, se presenta un ejercicio de escritura de un estudiante de Capavan:

Lo que nos permite contemplar que cada miembro de nuestra institución se abstiene de ir tras un beneficio personal, poniendo por encima el bienestar social, ambiental y cultural de cada una de las regiones que conforman nuestro país. Pues está dirigida sin tener excepción de personas, pues aquí no aplica la clasificación socioeconómica que se ha marcado durante toda nuestra historia a las comunidades, ni aplica la distinción cultural entre etnias, pues nuestro deber se basa y se extiende sin límite a garantizar y velar por los derechos de todos quienes habitan el territorio nacional.

Esto nos permite y nos lleva a cada rincón de nuestro país cuidando de aquellos campesinos en el pueblo más remoto, de estar en las carreteras de las principales ciudades, las orillas de los ríos, las fronteras y todos aquellos linderos que marcan a Colombia como territorio independiente y cada uno de sus recursos.

En el ejercicio anterior, los estudiantes debían elaborar un texto de opinión en relación con alguna temática de la cartilla "Volver a lo básico" y, a partir de allí, desarrollar su punto de vista. Si bien la escritura académica se les dificulta, la posibilidad de relacionar la temática con sus situaciones y experiencias particulares permitió evidenciar que el relato vuelve a tomar un papel protagónico en la configuración de su aprendizaje y la manera como lo retratan.

De otra parte, se demuestra que los estudiantes son sujetos cognoscentes, en la medida en que construyen la escritura no como un código de transcripción del habla sino como una representación del lenguaje (Lerner, 2001). En este aspecto se establece la estrecha relación que tienen los estudiantes con la narración (oral y escrita) y la experiencia para configurar su aprendizaje y formación académica. 
Estas experiencias de leer y escribir quedan grabadas en el cuerpo y lo constituyen, es decir, leer y escribir construyen sentidos corporales y emociones y viceversa: sentidos corporales y emociones construyen nuestras formas de leer y escribir. Todo ello genera el acercamiento o el distanciamiento con lo otro (cuerpo, lectura y escritura), o con los otros. (Cuervo, 2013, p. 3)

En ese orden de ideas, se analizó la relación entre la escritura de los estudiantes llevada a cabo a través de las herramientas digitales (para el aprendizaje colectivo, significativo y articulador) y aquella que fue realizada de manera independiente. En ambos casos, la experiencia y el relato tuvieron papeles protagónicos y fueron el punto de partida para la reflexión de los estudiantes.

La escritura, entonces, construye esas realidades vivenciadas por los sujetos, permite volver a mirar, volver a recordar, volver a sentir una situación o circunstancia que impacta la configuración existencial. La materia prima del aprendizaje de los militares es su propia experiencia y esto lo articulan con el conocimiento, las competencias y los saberes que se aportan desde la formación de la EsACE, que, en articulación con las Tic, marcan un nuevo punto de partida para la formación y capacitación de la Fuerza: una educación militar sin fronteras.

\section{La cartografía social pedagógica del aprendizaje en tiempos de pandemia}

Como se mostró en las líneas anteriores, la narrativa permite recuperar las experiencias y reconocer las trayectorias de aprendizaje. Asimismo, como afirma Bruner (2003),

los relatos no solo son productos del lenguaje, tan notable por su extrema fecundidad, que permiten narrar distintas versiones, sino que narrarlas muy pronto se torna fundamental para las interacciones sociales [...]. En este sentido, el relato se imbrica con la vida de la cultura, e inclusive se vuelve parte integrante de ella. (p. 53)

Por la importancia de narrar, y en relación con la narración para otros, el uso de la cartografía social pedagógica permite recuperar las interpretaciones y los análisis comunes sobre un fenómeno determinado. En sí, esta técnica de recolección de datos es una derivación de lo que ha sido la cartografía social 
pedagógica, usada por los investigadores sociales para recuperar las experiencias territoriales de las comunidades, por eso cuenta con una larga tradición y ha permitido el estudio y la comprensión de los fenómenos sociales desde la voz de los participantes. En los últimos años se ha venido consolidando el uso de la cartografía social pedagógica en contextos educativos (Barragán \& Amador, 2014). Este desplazamiento permite evidenciar las formas, los significados y las problemáticas que las comunidades educativas enfrentan en su quehacer diario. Tres elementos constituyen los pilares de la cartografía social pedagógica: el mapa, el territorio y el sistema de relaciones.

Con base en esta metodología, se analizó la construcción de los territorios por parte de los estudiantes, quienes muestran las diferentes relaciones que la pandemia ha generado en sus procesos de aprendizaje y otros aspectos relacionados con sus actividades laborales. Esta mirada colectiva de lo que acontece permite construir de manera conjunta un territorio epistemológico y trazar metas $\mathrm{u}$ acciones para las transformaciones.

Todas las cartografías fueron temáticas, pues, tal y como señalan Barragán y Amador (2014), "posibilitan comprender situaciones problemáticas, en términos de fortalezas y debilidades, que se convierten en posibilidades de transformación. Además, visibilizan situaciones de riesgo que puedan llevar a fortalecer redes y a tomar acciones concretas de transformación" (p. 259). De acuerdo con ello, el eje de la temática en torno al cual se construyeron las cartografías fueron los cambios percibidos en el aprendizaje.

La construcción del territorio y las convenciones son el resultado de la negociación de percepciones y la tematización de estas. Gracias a ello, se genera una mirada enriquecida del problema que deriva en categorías de análisis, las cuales se integraron al sistema de relaciones. Por eso, se presentan tres mapas diferentes, pero con elementos que pueden ser comunes. Por ejemplo, las líneas de comunicación, deseo, tensión y posibilidad. El uso de la tecnología produce una línea de tensión y deseo por cuanto genera ansiedad, estrés, debido a los retos que implica el manejo de nuevas herramientas, pero a la vez posibilita acceder de una manera más flexible a nuevos conocimientos y generar aprendizajes significativos. 
En este orden de ideas, los territorios ${ }^{6}$ fueron el resultado de la integración de estudiantes de varias escuelas del sistema de Educación del Ejército, de diferentes zonas del país, los cuales estuvieron distribuidos en dos grupos de trabajo. La mirada interescuelas fortalece la comprensión y el análisis del sistema educativo en su conjunto. De igual modo, la comprensión del territorio analizado desde otra perspectiva permite proponer otros ejes de comprensión y abordaje de lo pedagógico.

Los sistemas de relaciones tuvieron elementos comunes, por ejemplo, las convenciones que dieron cuenta del aprendizaje se relacionaron tanto con líneas de estrés - por la simultaneidad y multitarea de las actividades - como de oportunidad de alfabetización digital, ya que pudieron conocer herramientas que facilitaron la gestión de las actividades de lectura, escritura y de búsqueda de información.

En el primer mapa (figura 3), los estudiantes centraron su análisis en las diferentes dimensiones que han impactado la pandemia: convivencia, el bienestar y el tiempo.

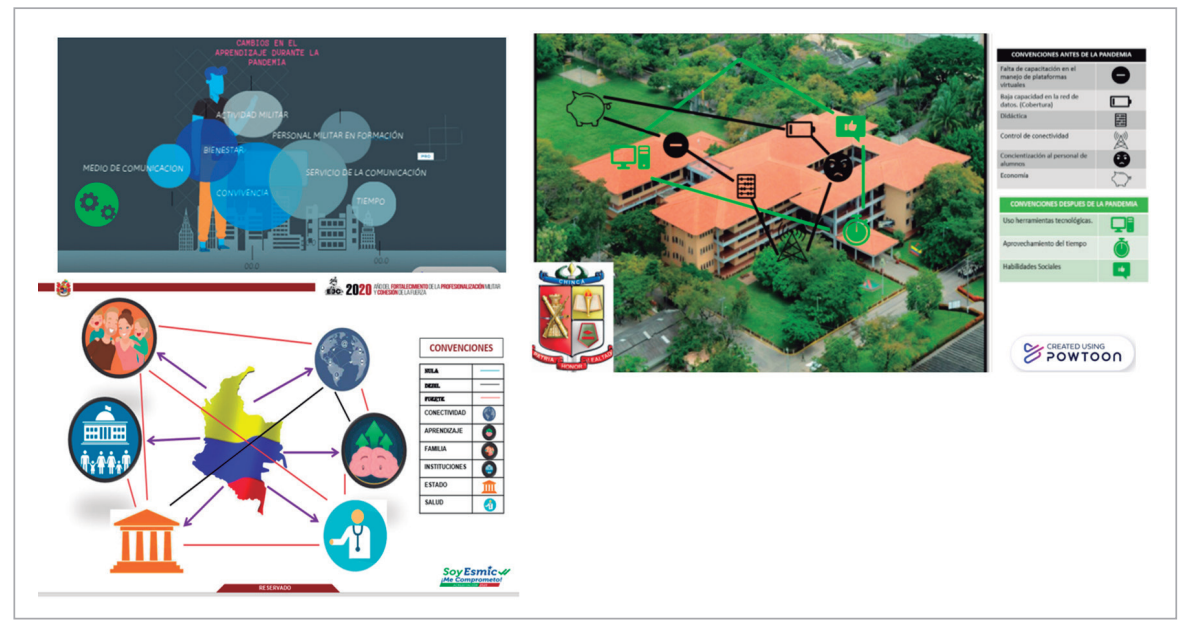

Figura 3. Cartografía social pedagógica-aprendizaje durante la pandemia. Dimensiones convivencia, el bienestar y tiempo.

Fuente: elaboración propia.

6 Es importante resaltar que la cartografía social comprende el territorio como un espacio simbólico más allá de los elementos físicos. Por eso cuando hablamos de los territorios identificados en la investigación se asume que son las construcciones intersubjetivas donde hay diferentes elementos que conforman el territorio asociados a las dinámicas de aprender en tiempos de pandemia. Estos territorios ampliaron la concepción de los espacios convencionales de sus unidades (armas, batallones, entre otros) y configuró un territorio que ha sido cartografiado pedagógicamente. 
Aunque el uso de tecnologías ha sido, en algunos casos, nuevo para el desarrollo de actividades en línea, les ha permitido afianzar sus conocimientos. En ese sentido, los oficiales y suboficiales afirman que "fue una oportunidad para aprender de las herramientas ofimáticas y para poder mirar otra forma de enseńanza y aprendizaje. Más que una barrera fue una oportunidad para conocer" (E05, septiembre de 2020). En cuanto al tiempo, consideran que la simultaneidad de tareas educativas y propias del ejercicio militar aumentó y por eso la gestión del tiempo fue un asunto primordial para el aprendizaje.

En la dimensión comunicativa y de bienestar, la experiencia de la educación en línea exigió superar las prácticas convencionales de pasividad frente al contenido expuesto por el docente, enfrentándolos a producciones en línea, foros, trabajo en grupo por salas y gestión de herramientas; una pedagogía de la interactividad, como señalan Aparici y Silva (2012) cuando afirman que la participación-intervención "no es solo responder 'si' o 'no' o elegir una opción determinada, supone interferir, intervenir en el contenido de la información o modificar un mensaje” (p. 15). Además, advierten que es necesario la permutabilidad-potencialidad, término que hace referencia a la posibilidad de hacer asociaciones y cambios gracias a la articulación de múltiples redes, con el fin de generar diversos horizontes de significados.

En la segunda cartografía (figura 4), los estudiantes resaltan los cambios en el aprendizaje a través de seis convenciones y cuatro relaciones, haciendo énfasis en las fortalezas y debilidades, antes y después de la pandemia. Entre los aspectos que consideran relevantes antes de la emergencia sanitaria señalan la existencia de las plataformas, pero su uso era esporádico debido a lo limitado de los conocimientos con respecto a su uso, lo que implicaba un desempeño básico en las competencias digitales. Asimismo, las didácticas antes de la pandemia no incorporaron las herramientas digitales, puesto que se usaban estrategias de aula centradas en el desarrollo de problemas que no requerían herramientas Tic. Durante la pandemia, los entrevistados consideran que las didácticas se han orientado al uso más efectivo de herramientas digitales que favorezcan el trabajo colaborativo, y a una mayor concientización por parte de los estudiantes sobre la regulación del aprendizaje. Asimismo, señalan que se aprovecha de mejor manera el tiempo y los recursos, gracias a que pueden profundizar en los temas. Las dinámicas de acompañamiento sincrónico y 
asincrónico han propiciado un mayor diálogo con los docentes. Desde la perspectiva de la pedagogía de la interactividad y del aprendizaje significativo, el docente debe garantizar

la posibilidad de significaciones libres y plurales, sin perder de vista la coherencia con su opción crítica, ha de estar abierto a ampliaciones y modificaciones propuestas por los alumnos. Una pedagogía basada en esa disposición a la co-autoría, a la interactividad, requiere la muerte de un modelo de profesor y el nacimiento de un docente democrático y plural. (Aparici \& Silva, 2012, p. 57)

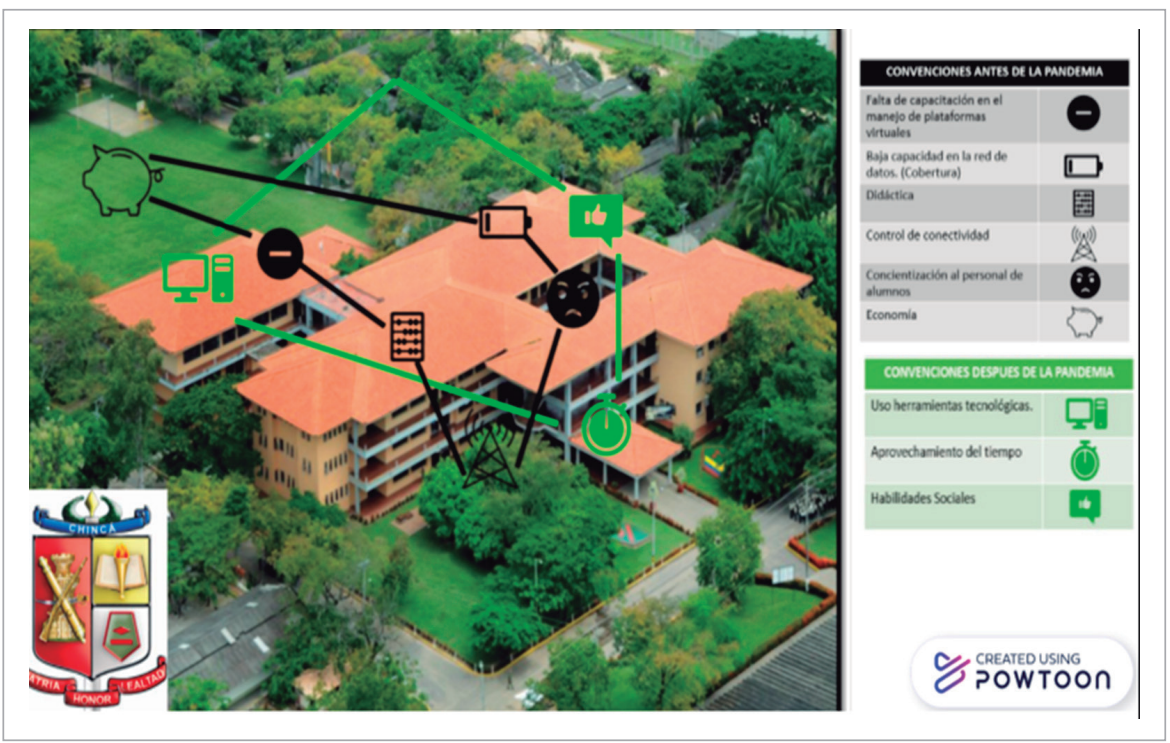

Figura 4. Cartografía social pedagógica-aprendizaje durante la pandemia. Cambios en el aprendizaje.

Fuente: elaboración propia.

En el tercer mapa (figura 5), los estudiantes mostraron tres líneas de relación: nula, débil y fuerte. Su perspectiva es más general y busca mostrar las relaciones entre las diferentes instituciones sociales, lo que explica las líneas entre las convenciones de conectividad, aprendizaje, familia, instituciones, Estado y salud. Para este grupo, las líneas débiles se relacionan con la conectividad, dado que es un factor que en tiempos de pandemia determina el acceso a los bienes culturales y a la educación; por tanto, consideran que este aspecto se debe fortalecer a corto plazo. Ahora bien, también consideran que el aprendizaje 
depende de sus condiciones propias y de la manera como logren gestionar su tiempo y sus esfuerzos.

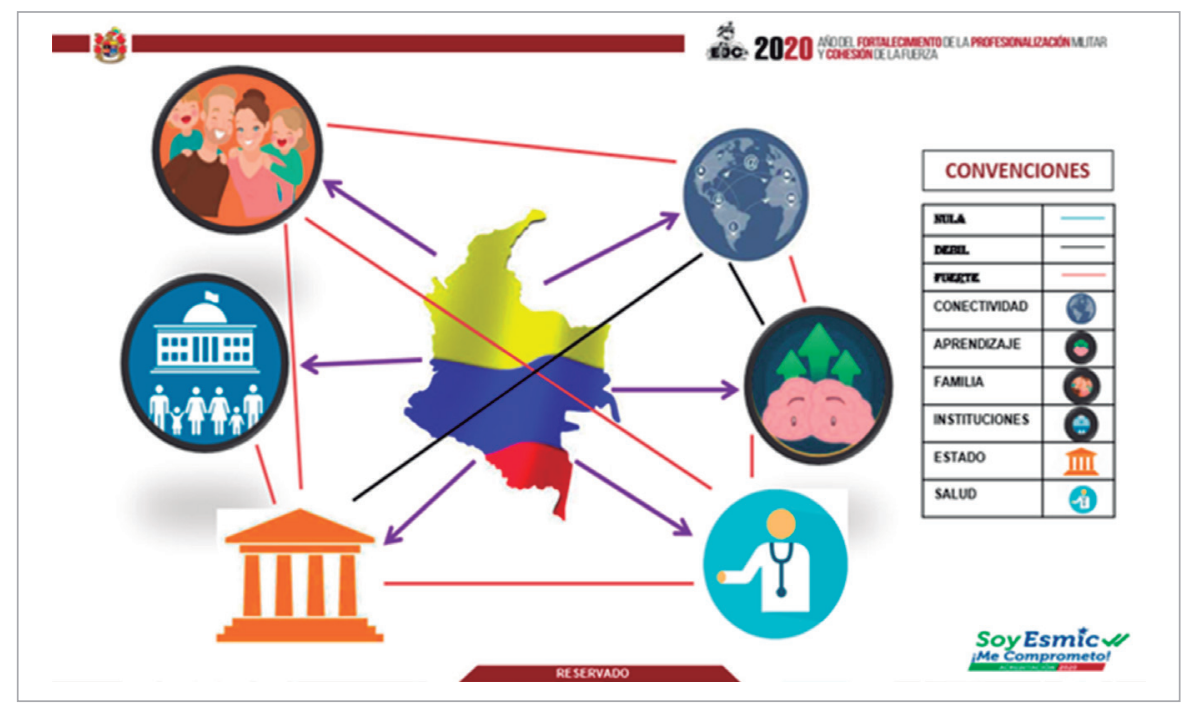

Figura 5. Cartografía social pedagógica-aprendizaje durante la pandemia. Relación entre las instituciones sociales.

Fuente: elaboración propia.

Esta lectura desde el colectivo evidencia que los aprendizajes generados en el marco de la pandemia transformaron las concepciones de aprendizaje, didáctica y currículo, puesto que las interacciones asincrónicas y sincrónicas pusieron de relieve el papel fundamental del docente y la responsabilidad del estudiante en su propio proceso formativo.

\section{Discusión}

Los resultados presentados representan las percepciones de los estudiantes de la EsACE con respecto a sus necesidades de aprendizaje y a la mediación tecnológica para sus procesos formativos.

Como se propuso inicialmente, la indagación buscó analizar el impacto de las herramientas tecnológicas en la formación de los oficiales y suboficiales de la EsACE y el tránsito y las transformaciones que esto ha implicado en su cotidianidad, en el marco de la emergencia sanitaria, lo cual permitió trazar una ruta orientadora para identificar aquellos aspectos que desde las estrategias 
y propuestas académicas y formativas de la EsACE optimizaran la capacitación del personal militar, a través del fortalecimiento del uso de las herramientas tecnológicas con fines pedagógicos, partiendo de que la mayoría de los estudiantes llegan a la Escuela con conocimientos mínimos o básicos de la tecnología educativa.

Entre tanto, se hace patente la existencia de espacios de diálogo e intercambio de visiones en torno al aprendizaje y la cotidianidad, y se identifican algunos espacios enriquecidos de aprendizaje que surgen como resultado de la "nueva normalidad" y la preparación de todos los estudiantes a través de las plataformas tecnológicas. Asimismo, el aprendizaje en línea y las tecnologías de interacción que se evidenciaron en la fase de indagación y exploración, posibilitaron, como señalan Aparici y Silva (2012), "una pedagogía de la interactividad que establece nuevos escenarios educativos".

Pensar en la formación de los estudiantes que son parte del Ejército Nacional ya no consiste solamente en la actualización de mallas curriculares, de definición de perfiles, de la configuración y consolidación de los módulos táctico, técnico, socio-humanístico e investigativo y las competencias con las que deben contar los estudiantes para desempeñarse en diversos roles y escenarios militares, sino que implica pensar en un impacto aún mayor, que resulta revelador, y que está relacionado directamente con las estrategias que se adelantan desde la EsACE para aportar significativamente a la formación militar desde un contexto virtual. Esto comprende el tránsito inevitable entre las aulas, la evaluación y las actividades presenciales, a los espacios de educación virtual, en donde las características, las formas de evaluar, las herramientas y las competencias son completamente diferentes. Para lograr optimizar estos escenarios digitales en pro del aprendizaje, se hace indispensable, a partir de la experiencia subjetiva de los militares, la capacitación y actualización de docentes y estudiantes, así como implementar nuevas estrategias que se desarrollen como resultado de los hallazgos evidenciados durante el año 2020 y lo corrido del 2021.

Entre tanto, esa inclusión de nuevos paradigmas educativos y de las propuestas de nuevas epistemologías en el campo educativo deben ser consolidadas dentro de espacios de diálogo, interacción, análisis de la apropiación del conocimiento y el aprendizaje significativo, que, en resumidas cuentas, 
permitan aportar de manera contundente a nuevas investigaciones y propuestas que surjan como resultado de la aplicación de herramientas, prácticas y saberes pedagógicos, nuevas pedagogías y alfabetización digital, que construyan y den paso a nuevas concepciones educativas.

De otra parte, el relato, como materia prima para identificar experiencias y narrativas propias de cada estudiante, genera un espacio provechoso y enriquecedor que toma en cuenta antecedentes formativos y cotidianos, y se suma a propuestas que — más allá de solamente contar y registrar esas memorias subjetivas y su incidencia e impacto en el aprendizaje de los estudiantesreflejan un panorama de construcción permanente en el que las tecnologías no son protagonistas de estas modalidades formativas, sino mediadoras, y donde la atención se centra en la experiencia del estudiante como usuario digital, como individuo que aprende a través de la tecnología y, sobre todo, como sujeto pensante que configura realidades a partir de lo que percibe e interpreta de su entorno.

No se trata entonces solamente de alfabetizar digitalmente a la comunidad académica, sino de tomar en consideración aspectos que se han develado en la presente investigación, para que la educación virtual no carezca de sentido integral y humano, y se ocupe también de identificar y definir esas formas de aprendizaje propias de los estudiantes que atraviesan la transición entre su desempeño en el área de operaciones y de combate, para convertirse en usuarios digitales con participación a través de las plataformas tecnológicas.

Así pues, la educación virtual nos ofrece, hoy en día, un océano de posibilidades para el logro no solo de las mentadas metas del milenio tan cacareadas por los organismos internacionales sino, también, para armonizar y poner en juego la verdadera unidad en la diversidad, propia del ser humano, a través de infinidad de procesos cognitivos, reales, simbólicos y virtuales. (Nieto, 2012, p. 146)

En este punto, cabe anotar que resulta fundamental que las escuelas que forman parte del Sistema de Educación del Ejército Nacional apuesten por potenciar la calidad educativa en los procesos que se vienen implementando para la capacitación formativa de los hombres que integran la Fuerza, y tengan la capacidad de responder de manera asertiva a los retos que presenta el panorama educativo, buscando la formación integral y la optimización de la forma- 
ción de sus hombres, pues, tal como lo contempla el Proyecto Educativo de las Fuerzas Armadas,

Este sistema liderará la formación de militares y policías, fundamentada en los desafíos propios de la modernidad, mediante la investigación científica, el desarrollo tecnológico y la innovación, aptos para el trabajo en equipo y con capacidad de adaptación al cambio. (Ministerio de Defensa Nacional, 2008, p. 35)

El cambio y los retos en educación han servido como punto de partida para implementar estrategias y para continuar con la consolidación de propuestas que den espacio a múltiples alternativas educativas, que deben ajustarse a las necesidades del personal militar, pues no se puede desconocer que la realidad de los oficiales y suboficiales no se compara con la realidad de la población civil. Debe tomarse en cuenta que, aunque el Ministerio de Educación Nacional articula y realiza seguimiento de los lineamientos y los programas que se ofertan en la EsACE, la educación militar busca equipar a sus hombres y mujeres con los conocimientos necesarios para afrontar los retos que se presenten, articulando experiencias y transformaciones para una educación sin fronteras.

\section{Conclusiones}

La crisis sanitaria aceleró el uso de la tecnología en las escuelas e instituciones de educación superior, evidenció la crisis del sistema tradicional y promovió nuevas formas de generar conocimiento, gracias a las lógicas propias de la cibercultura, donde la conectividad, la interacción y la hipertextualidad rompen las fronteras y permiten comunicarnos de manera rápida y asincrónica. Sin embargo, falta mucho camino por recorrer, puesto que se deben fortalecer los equipos docentes, promover las comunidades de aprendizaje y superar la instrumentalización de la tecnología.

Como se ha podido apreciar, volver a los sujetos a través de sus relatos permite identificar trayectorias de aprendizaje importantes, establecer rutas pedagógicas más acordes a sus necesidades educativas, orientar procesos de formación integral, así como estimar los alcances y ajustes que las propuestas curriculares del Sistema Educativo de la Fuerza deben realizar, teniendo en 
cuenta las experiencias de enseñanza mediadas por la tecnología que las escuelas de formación y capacitación han tenido. Este conocimiento, que proviene de la praxis, contribuye a las metas de profesionalización y consolidación de un Ejército multimisión.

El diálogo pedagógico es fundamental para una educación sin fronteras, donde la tecnología con fines educativos facilite el diálogo de saberes que aporten al desarrollo doctrinal de la Fuerza. Por tanto, es importante reflexionar sobre el tránsito que hacen oficiales y suboficiales que vienen de zonas de operación al llegar a las aulas, dado que es un momento único para sistematizar el conocimiento y las reflexiones que los hombres y las mujeres que forman parte de la institución han construido. Reconocer sus debilidades, honrar sus proezas y fortalecer sus capacidades favorecerá la actualización de los conocimientos propios de las ciencias militares.

En este contexto, valga recordar que aprender significativamente involucra a la persona en su totalidad. Tanto los procesos socioafectivos como los cognitivos son de suma importancia, y si se desarrollan de manera experiencial, favorecen la conexión con otros conocimientos previos.

De acuerdo con Hernández (1998), el aprendizaje participativo implica que el estudiante haga uso de sus recursos, despliegue sus capacidades porque se siente motivado y parte de una comunidad que valora y reconoce sus ideas. Sin ninguna duda, resulta evidente la existencia y desarrollo de aprendizajes significativos, procesos metacognitivos y compromisos de oficiales y suboficiales con respecto a seguir enalteciendo a la institución a través de la profesionalización.

Esta pandemia mostró la vulnerabilidad humana, pero también la resiliencia para afrontar las dificultades y volverlas oportunidades de cambio. Gracias a ello podemos construir y reconstruir esta mirada etnográfica de los cambios que han afrontado los militares, la cual resulta valiosa por cuanto nos ayuda a fortalecer las propuestas educativas de la Escuela de Armas Combinadas del Ejército Nacional. 


\section{Referencias}

Acero, J. (1998). Filosofía del lenguaje I. Semántica. En Enciclopedia Iberoamericana de Filosofía. Editorial Trotta.

Aparici, R., \& Silva, M. (2012). Pedagogía de la interactividad. Comunicar, 19(38), 51-58.

Arboleda, L. (2007). El grupo de discusión como aproximación metodológica en investigaciones cualitativas. Revista Facultad Nacional de Salud Pública, 26(1), 69-77.

Ausubel, D. P. (1978). En defensa de los organizadores avanzados: una respuesta a las críticas. Revisión de la Investigación Educativa, 48(2), 251-257.

Barragán, D., \& Amador, J. (2014). La cartografía social-pedagógica: una oportunidad para producir conocimiento y re-pensar la educación. Itinerario educativo, 28(64), 127-141.

Barthes, R. (1996). Introducción al análisis estructural de los relatos. Tiempo Contemporáneo.

Bauman, Z. (2015). Modernidad líquida. Fondo de Cultura Económica.

Bolívar, A., \& Domingo, J. (2006). La investigación biográfica y narrativa en Iberoamérica: Campos de desarrollo y estado actual. Forum: Qualitative Social Research, 7(4). http:// jbposgrado.org/icuali/La\%20investigacion\%20biografica\%20y\%20narrativa\%20en\%20 iberoamerica\%20\%20\%20.pdf

Bruner, J. (2003). La fábrica de historias. Derecho, literatura, vida. Fondo de Cultura Económica de España.

Cassany, D. (2012). En_linea. Leer y escribir en la red. Anagrama.

Cobo, C. (2007). Modelo de aprendizaje abierto. Innovación Educativa, 7(41), 5-17.

Cuervo, C. (2013). Leer y escribir como experiencias corporales. Pontificia Universidad Javeriana.

Díaz, F., \& Hernández, G. (2010). Estrategias docentes para un aprendizaje significativo: una interpretación constructivista. McGraw-Hill Interamericana.

Gómez Sánchez, C. (2016). Aragnuren \& Ricoeur. La vida como narración. Revista Internacional de Filosofía, (68), 57-83.

Granados, L. (2016). Narrativas y existencia. Narrar la vida como mediación metodológica para reconstruir la existencia herida. Revista Medicina Narrativa. Escritura Creativa Médica, 6(2), 5-17. https://bit.ly/30VhHqS

Guber, R. (2001). La etnografía: método, campo y reflexividad. Grupo Editorial Norma.

Hernández, G. (1998). Paradigmas en psicología de la educación. Paidós Ibérica.

Ministerio de Defensa Nacional. (2008). PESE, Plan Estratégico del Sistema Educativo de las Fuerzas Armadas 2007-2019. https://www.mindefensa.gov.co/irj/go/km/docs/ Mindefensa/Documentos/descargas/estrategia_planeacion/desa_capital/Pagina/PESE_ FINAL.pdf

Moreira, M. (2012). ¿̇Al final, qué es aprendizaje significativo? Revista Qurriculum, (25), 29-56. https://riull.ull.es/xmlui/handle/915/10652 
Nieto, R. (2012). Educación virtual o virtualidad de la educación. Revista Historia de la Educación Latinoamericana, 14(19), 137-150. https://www.redalyc.org/articulo. oa? id $=86926976007$

Páramo, P. (Comp.). (2016). La investigación en ciencias sociales: estrategias de investigación. Universidad Piloto de Colombia.

Vasilachis, I. (coord.). (2006). Estrategias de investigación cualitativa. Editorial Gedisa. http:// investigacionsocial.sociales.uba.ar/wp-content/uploads/sites/103/2013/03/Estrategiasde-la-investigacin-cualitativa-1.pdf

\section{Bibliografía consultada}

Bárcena, F. (2002). Educación y experiencia en el aprendizaje de lo nuevo. Revista Española de Pedagogia, (223), 501-520. https://bit.ly/34M2JEM

Ejército Nacional de Colombia. (2015). Proyecto Educativo Institucional. Jefatura de Educación y Doctrina.

Martínez, (2001). Subjetivación y lenguaje. Pontificia Universidad Javeriana.

Ministerio de Defensa Nacional. (2010). SEFA. Lineamientos Curriculares Fuerzas Militares. https://docplayer.es/136655835-Sefa-lineamientos-curriculares-fuerzas-militares.html

Montaluisa, A., Salas, E., \& Garcés, L. (2019). Los estilos de aprendizaje según Honey y Mumford y su relación con las estrategias didácticas para matemáticas. REIRE Revista d'Innovació i Recerca en Educació, 12(2), 1-16.

Organización de las Naciones Unidas. (2020). La educación en tiempos de la pandemia de COVID-19. Cepal- Unesco.

Pantoja, M., Duque, \& L., Correa, J. (2013). Modelos de estilos de aprendizaje: una actualización para su revisión y análisis. Revista Colombiana de Educación, (64), 79-105. https://doi.org/10.17227/01203916.64rce79.105

Rodríguez, R. (2018). Los modelos de aprendizaje de Kolb, Honey y Mumford: implicaciones para la educación en ciencias. Sophia, 14(1), 51-64. 